\title{
A Design of Personal Learning Network on Social Networking Tools with Gamification for Professional Experience
}

\author{
https://doi.org/10.3991/ijet.v16i18.25159 \\ Janejira Arsarkij $\left.{ }^{\bowtie}\right)$, Thanomporn Laohajaratsang \\ Chiang Mai University, Chiang Mai, Thailand \\ janejira_a@cmu.ac.th
}

\begin{abstract}
This research aimed to design a novel teaching and learning process in the professional experience training. The Successive Approximation Model (SAM) was applied in the design steps. The attainment of the designed framework derived from numbers of theoretical reviews, as well as the analytical data collected from the expert interviews. The proposed framework included the components of a Personal Learning Network (PLN), the process of PLN, and the professional experience procedure. The components of PLN were: learning resources, learning tools, learning content, and learning activities. In addition, the process of PLN consisted of Creation, Connection, Cognition, and Contribution. The professional experience incorporated nine main activities particularly, enrolling in the course, joining three compulsory seminars, doing two major periods of internship, mentor visiting, submitting assignments, and completing the course. These three concepts were combined into the framework of integrated learning activities, which occurred in social networking tool, Course Networking $(\mathrm{CN})$. It operated as the learning tool utilized the newly created addable badges as a part of gamification features. The assessment results from the eleven experts revealed that the teaching and learning practice using personal learning networks on social networking tools with gamification in the professional experience proved to have high levels of standard evaluation, innovative attributes, design process, teaching and learning procedure, and teaching and learning activities.
\end{abstract}

Keywords-Personal Learning Network, PLN, Social Networking Tools with Gamification, Professional Experience

\section{Introduction}

The use of internet technology and social media has become an essential part of the lives of billions of people around the world. People are likely to use social media as their main source of information, entertainment, and social interaction [1]. The accelerated growth of digital technologies provides various opportunities for educational development, especially in learning theories and teaching and learning processes. The internet and social networks have recently become necessary tools for communication, 
teaching and learning, in the especially COVID-19 pandemic that has forced educational institutions worldwide to shift to online learning as the new normal for all kinds of learning content [2], [3], [4]. Teachers and educators have attempted to find the most suitable teaching and learning frameworks and methods to implement in their pedagogy [5], [6], [7], [8]. One vital aspect of on-site and non-classroom learning is the professional experience.

Professional experience refers to real-world practical work in fields related to a student's major, and is part of many university programs. Its objective is to provide opportunities for students to develop professional skills while undertaking practical learning. Students gain professional experience by working with organizations related to their fields and they have to complete their academic work required for completing their degree program. The professional experience requires students to have high level of self-directed learning as part of developing their personal attributes alongside their professional attributes [9].

Personal Learning Network (PLN) has previously been applied in various fields of educational research including professional experience development [10], [11]. PLN is defined as connectivism functions as a self-designed, self-initiated system that develops important skills for lifelong learning [12]. PLN focuses relate to learning in the digital age by supporting formal and informal learning. The use of PLN combined with online learning can promote the professional experience or internships in various learning disciplines, since PLNs are usually created in social networking platforms used as communication tools to connect learners and teachers. In order to effectively promote the professional experience in an online context, the selection of tools for a PLN should provide suitable learning environments for personalized learning.

Social networking tools or platforms used in PLNs were shown to be significant factors in student achievement in a PLN. Social networking sites were reported to facilitate the interaction in online learning [13], [14]. Social network platforms can be tools for communication, sources of information and social interaction [15], [16], [17]. However, it is important to choose the suitable and effective platform or tools in order to produce the best outcomes since it could lead to negative influence [18], [19], [20]. The use of social networking tools associated with gamification can enhance the learning, and the gamified social network can improve students' engagement and motivation for course content in pedagogical practices [21].

Gamification is the practice of game-like elements including in non-game contexts to motivate desired behaviors [22]. Gamification was mentioned as part of the main components of the next-generation Learning Management System (LMS) include: (1) Learning Tools Interoperability (LTI); (2) analytics, advising and assessment in learning; (3) social media design formats; (4) smart phone elements of content and functionality; (5) game components; and (6) artificial intelligence (AI) functions that allow students to personalized their learning [23]. There are many LMS tools designed in the form of apps and websites that allow people to use social networking tools in an educational context. Flores [24] stated that gamification features are frequently used by various learning apps, websites, and platforms such as Duolingo, Class Dojo, Edmodo, Zondle, Socrative, and Brainscape. Among the online learning platforms, Course Net- 
working $(\mathrm{CN})$ was suggested as a good example of the recently developed LMS because it is grounded in modern teaching theories and it implements learning management systems design concepts and components [23].

It is important to understand how PLN is maintained and nurtured, and to study how the combination of social networks and gamification function enhance learners' selfdirected learning, particularly for the post-secondary education level in this study. This is to gain the most benefits of PLN on social networking tools with gamification in order to produce a novel pedagogy under the context of professional experience learning.

\subsection{Research Objective}

The research objective for this study was to design an innovative teaching and learning process using PLN on social networking tools with gamification for the professional experience program.

\section{Literature Review}

\subsection{Personal Learning Network}

The term "personal learning network" (PLN) was first coined by Daniel Tobin [25] on his Corporate Learning Strategies websites under "Building Your Personal Learning Network". PLN can be defined as a "system of interpersonal connections and resources that support informal learning" [26]. In addition, it was indicated that the terms "Professional Learning Network" and "Personal Learning Network" are often used interchangeably. However, a study by Grant \& Hsu [11] differentiated the terms by using "PLNs" for personal learning network and "ProLns" for professional learning network. In this study, PLN refers to personal learning network since the term PLN is not only used for professional development purposes but also non-professional objectives, such as students or individuals who use PLN for their personal learning or interests.

There is scarce publication showing detail or information about types of PLN. Warlick [27] stated that there are three major types of PLN considering time and accessibility including personally maintained synchronous connections, personally and socially maintained semi-synchronous connections, and dynamically maintained asynchronous connections. This indicates that a PLN is not place or time bound; it is asynchronous, available at any time and place with internet access, and, in some cases, even without internet access.

Personal Learning Network Components. A PLN normally includes both face-toface and virtual professional connections, and is composed of people who learn and share ideas together, as well as resources, tools, and materials that support their learning [28]. Jarche [29] demonstrated that a PLN consists of tools, artefacts, processes, and physical connections. Bauer [30] presented that the components of a PLN include resources, people, and multimedia web resources. Rajagopal et al. [31] pointed skill, ac- 
tivity, and attitude intention were the main components of a PLN. Tsolakidis [32] implied that PLN comprised of: tools that facilitate the improvement of network, people who build network, relationships of individual, connections, and contacts. Carter \& Nugen [12] stated that a PLN is produced when learners participate in several virtual communities of practice wherein learners interact online, and form knowledge by sharing and creating learning content.

From numbers of the theoretical reviews, the four components of PLN are: (1) learning resources, which include information, people, and networks; (2) learning tools, which are the devices, applications, platforms or networks; (3) learning content which means any kind of knowledge content, particular subject contents, or any area of interest that learners study, and; (4) learning activities, defined as the activities or processes that learners perform in order to gain knowledge or to contribute knowledge.

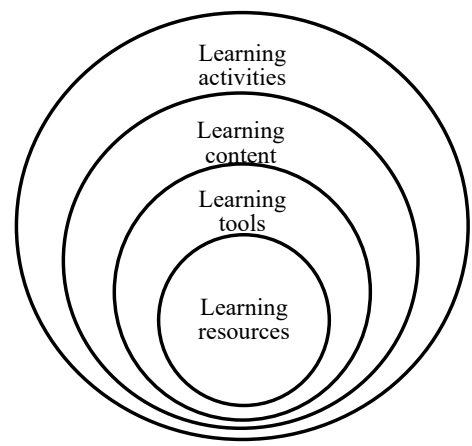

Fig. 1. Personal Learning Networks Components

Personal Learning Network Conceptual Models. The concept of PLN is seen as a part of a personal learning environment (PLE) which has been explored and designed presenting the relationships among the personal learning network, personal web tools, and personal learning environment that individuals use to support their learning [33]. Couros [34] distinguished the concept of a PLE from that of a PLN by explaining that PLEs are the tools, artefacts, processes, and physical connections that allow learners to control and manage their learning, whereas PLNs extend this model to include the personal connections mediated through PLEs.

The concept of personal learning networks has been explored and published in formal research articles as well as informal publications. Swanson [35] explained that digital tools and social media networks can be embraced by a learner to create connections with other learners, in order to generate personal learning through curation, reflection, and contribution. Through curation, the learner can gather relevant resources. Then, with reflection, the learner engages new information with existing background knowledge. Finally, during contribution, the learner shares what he or she has learned with their learning connections. Similarly, Jarche [29] disclosed that the way to see network learning is as a continuous process of seeking, sensing, and sharing. He defined seeking as searching out and staying up to date on information. Sensing is the way that 
an individual personalizes and uses information. Sensing consists of reflection and putting the acquired information into practice. Sharing includes exchanging resources, points of view and experiences with contact networks. Rajagopal et al. [31] identified that in order to make the best use of the learning opportunities in personal learning networks, learners need to proceed in three significant tasks that form the basis for other activities within the network: building connections, maintaining connections, and activating connections with selected persons for the purpose of learning. Moreover, the factors influencing choices in building, maintaining, and activating personal learning networks were grouped and presented in relation to three major sections: (1) personal interests; (2) contact and relationship with learners; and (3) external characteristics of the work environment.

From many of the theoretical reviews, the process of a PLN consist of four main attributes or activities (4Cs), which are: Creation, Connection, Cognition, and Contribution. This process was combined in the designed process of professional experience teaching and learning (Figure 2).

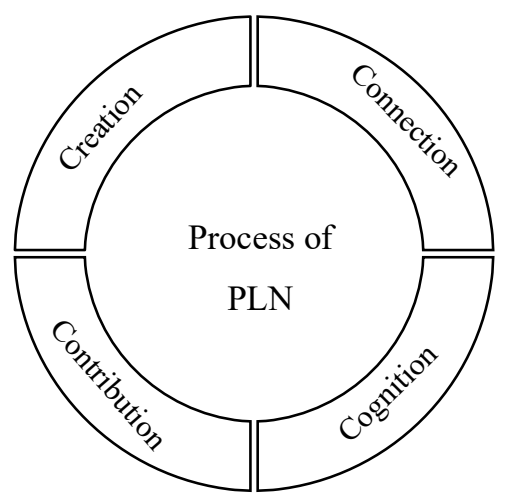

Fig. 2. Process of Personal Learning Network (4Cs)

- Creation: a learner creates a virtual identity through applications, tools, websites, or platforms in order to activate the individual account and start connecting with others. These days, most people have multiple virtual identities on their social network accounts.

- Connection: a learner connects to some resources for learning by joining social networking tools or platforms, and linking knowledge from information resources, people, organizations, or communities. In this stage, a learner bridges knowledge from different sources with their own performances and experiences.

- Cognition: a learner cognitively learns and perceives information about their interests from networks, resources, people, or communities. In this state, a learner may just passively look around for the required information, or collect information of their interest, or they may take a more active role by performing some actions or reactions such as asking questions, making questions, or doing anything to get the needed information. 
- Contribution: a learner contributes information or knowledge which could be in form of posting comments, giving recommendations and suggestions when a learner feels confidence that they have enough information to share or when they find some information that might be interesting or useful to others.

These four main activities could occur at any stage of learning since a learner could create their new virtual identity at any time if they find a new platform or networking tool to connect with others. Likewise, a learner could cognitively learn by connecting different resources of information in various forms of content such as blogs, vlogs, videos, posts, or comments before connecting with others at a platform. Moreover, learners might feel that they would like to randomly interact with others, to contribute some information or ideas with others in a particular platform or networking tool when they think it is interesting.

\subsection{Social Networking Tools with Gamification}

Internet technology has encouraged the development of applications, websites, and platforms for learning. Teachers and scholars have increasingly turned their attention to educational networking, particularly the use of social networks for educational purposes. Social networks are platforms or tools that facilitate the building of social relationships among people of different races and provide opportunities for them to share interests, activities, backgrounds or real-life connections [36]. A social network consists of the individuals and the interactional connections or ties between people or learners. The interactions may take the form of exchanging comments, knowledge, materials, resources, and advice [37]. Therefore, the selection of tools used to create a PLN should provide suitable learning environments for personalized learning.

Popular social networking sites that are often used as learning tools by educators include Twitter, LinkedIn, Google+, YouTube, and Facebook. There are many social networking tools designed with the LMS tools. The implementation of the LMS could be in the form of apps and websites that can be used in educational contexts. The application of gamification in education can be seen in the form of software tools such as e-learning, web-based learning, LMS, and Moodle learning platforms [38].

Gamification is the use of game elements in non-game contexts to motivate desired behaviors in students [22]. Gamification learning technique employs game dynamics, mechanics, and forms the non-game situation [39]. Kapp [40] pointed out that gamification is a useful tool in learning professionals because it includes some of these elements of contemporary games such as points, badges, progress bars/progression charts, leader boards, performance graphs, levels, quests, social elements, avatars, and rewards. These elements of gamification in learning more broadly, motivate studentdriven work along with communication and collaboration. The gamification features could encourage learners' performance and create measurable feedback [41]. There are various types of tools in educational technology that allow educators to have possibilities in using gamification with different target audiences and combining gamification with the appropriate learning approach or strategy for each audience. The examples of the gamified platforms for learning used in educational study were ClassCraft, Rezzly, 
Seppo, Youtopia, Kahoot, Languagenut, FluentU, The Language Game, and MindSnacks [42], [43].

In this study, Course Networking (CN) was implemented as social networking tool since it is grounded in modern teaching theories with gamification design concepts and components. The $\mathrm{CN}$ features gamification elements such as badges, leaderboards, progress reports, as well as a learner analytic system. It can be used on both personal computer and smartphone application. Moreover, the $\mathrm{CN}$ allows instructors to design and add-on their own badges for any particular rewarding purposes.

\subsection{Professional Experience}

The professional experience has the nature of on-site-learning or non-classroom learning. The professional experience training program aims to enable learners to gain and apply knowledge learned in the workplace, and become competent in practical skills by learning in real-world practical situations as their life-long learning skills. Chuenpraphanusorn et al. [44] stated that some universities in Thailand adopt different models and methods of education management and provide good education and course curriculum for professional experience programs. According to the professional experience program details at the university in this study, fourth year students in the professional experience program have the responsibility of finding a workplace in their first semester, and then go to work at the approved organization in the second semester. During the practicum, which is their work at the organization, the student interns must join three physical classes which are called professional experience seminars. These include an orientation seminar, a midterm seminar, and the final seminar. The students need to perform as a student intern at the organization they choose, and submit academic assignments as requirements to complete the professional experience program. The procedures for completing the professional experience program are presented in the figure 3 .

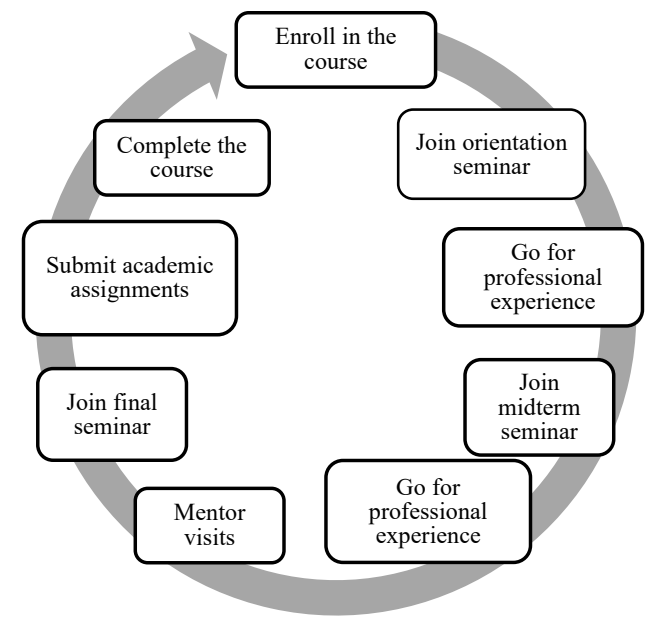

Fig. 3. The professional experience procedure 
Some problems can occur during the professional experience, including problems with the mentoring system due to long distances which the mentors have to travel for meetings at different locations, and problems with some student interns at the workplace, such as the lack of discipline and punctuality. There are also some problems related to the academic requirements of the university, such as delayed submission of work and incomplete tasks. The student interns are required to possess the self-directed ability to satisfy all the requirements of the academic program, such as joining three compulsory seminars, submitting all assignments including the professional experience daily report, term papers, and evaluation from organizations, and they must also remain responsible for work-integrated learning task at their workplaces. This field experience program can play an important role in reflecting the required qualifications of graduates, and revealing the obstacles faced by student interns, employers, and organizations.

\section{$3 \quad$ Methodology}

The methodology of this research included three phases: preparation, iterative design, and iterative development. Each of these is part of the process of the Successive Approximation Model (SAM) instructional design process [45].

\subsection{Preparation}

This research started with information gathering by conducting literature reviews to identify relevant theory, concepts, and research related to the use of personal learning networks (PLNs) on social networking tools with gamification, as well as the procedures of the professional experience training program. The analysis of performance, and problems in the professional experience was conducted using surveys and interviews with people involved with the professional experience including the student interns and lecturers. In addition, the framework Savvy Start was applied using interviews with experts in the fields of learning network technology, professional experience, and curriculum and instruction to discuss the use of PLNs on social networks with the gamification learning concept applied to the professional experience training. The data was collected, analyzed and synthesized for the design stage.

\subsection{Iterative design}

The establishment of the design was commenced as the prototype teaching and learning process using information from theoretical reviews, and information gathered for the teaching and learning process for the professional experience. Then the information from the Savvy Start discussion was added to scaffold the prototype of the personal learning network on social networking tools with gamification in the professional experience program. Moreover, the instruments for evaluation were designed and developed for the process evaluation. 


\subsection{Iterative development}

The evaluation from the experts was conducted. In this phase, the designed framework of the teaching and learning process was presented to eleven experts including five experts from the area of technology for learning, four experts from the field of professional experience learning, and two experts from the curriculum and instruction area. In order to validate the designed teaching and learning process framework, the eleven experts were asked to evaluate the designed teaching and learning process using a five-point Likert Scale which ranged from strongly agree/ excellent/ very appropriate (5 points) to strongly disagree/very poor/very inappropriate (1 point). The areas of assessment consisted of: evaluation standards [46]; innovation attributes [47] since this was considered an innovation in the teaching and learning procedure; design process [45]; teaching and learning procedure [48]; and teaching and learning activities regarding PLN practice. Moreover, the experts were asked to give their opinions and suggestions regarding the framework of the use of PLNs on social networking tools with gamification in teaching and learning in the context of the professional experience.

\section{$4 \quad$ Results and Discussion}

\section{$1.8 \quad$ Research Results}

The following shows the results of the assessments by the eleven experts including five experts from the area of technology for learning, four experts of professional experience learning, and two experts from curriculum and instruction area. The results are displayed in five categories. First, the results of the standard of evaluation are indicated in Table 1. Second, the outcomes of the innovative attributes' assessment are shown in Table 2. Third, the consequence of the design process evaluation is defined in Table 3. Fourth, the conclusion of teaching and learning procedure appraisal are revealed in Table 4. Finally, results of the evaluation of teaching and learning activities using personal learning network on social networking tools with gamification in the context of the professional experience is shown in Table 5.

Table 1. Results of standard of evaluation [46]

\begin{tabular}{|l|c|c|c|}
\hline \multicolumn{1}{|c|}{ Areas of assessment } & Mean & Mode & S.D \\
\hline Utility Standards & 4.75 & 5 & .371 \\
\hline Feasibility Standards & 4.84 & 5 & .302 \\
\hline Propriety Standards & 4.67 & 5 & .338 \\
\hline Accuracy Standards & 4.85 & 5 & .311 \\
\hline Overall & 4.78 & 5 & .085 \\
\hline
\end{tabular}

The results of the evaluation standard displayed an overall score of 4.78 , which proved the experts agreed that this teaching and learning procedure met the program evaluation standard. The Standard of Evaluation areas included utility standards (4.75), feasibility standards (4.84), propriety standards (4.67), and accuracy standards (4.85). 
Table 2. Results of the innovative attributes assessment [47]

\begin{tabular}{|l|c|c|c|}
\hline \multicolumn{1}{|c|}{ Areas of assessment } & Mean & Mode & S.D \\
\hline Relative Advantage & 4.64 & 5 & .427 \\
\hline Compatibility & 4.58 & 5 & .340 \\
\hline Complexity & 4.30 & 5 & .459 \\
\hline Observability & 4.76 & 5 & .368 \\
\hline Trialability & 4.73 & 5 & .360 \\
\hline Overall & 4.60 & 5 & .183 \\
\hline
\end{tabular}

The attributes of innovation were evaluated since this project was considered to be the design of an innovation in teaching and learning process. The attributes of innovation consisted of relative advantage (4.64), compatibility (4.58), complexity (4.30), observability (4.76), and trialability (4.73). The results indicated that the experts agreed that the use of PLNs on social networking tools with gamification has all the attributes of innovation in teaching and learning procedure.

Table 3. Results of design process assessment [45]

\begin{tabular}{|l|c|c|c|}
\hline \multicolumn{1}{|c|}{ Areas of assessment } & Mean & Mode & S.D \\
\hline Preparation Phase & 4.91 & 5 & .302 \\
\hline Iterative Design Phase & 4.91 & 5 & .302 \\
\hline Iterative Development Phase & 4.91 & 5 & .302 \\
\hline Overall & 4.91 & 5 & 0 \\
\hline
\end{tabular}

This study implemented the Successive Approximation Model (SAM) as the instructional design process comprised of three phases: the preparation phase, the iterative design phase, and the interactive development phase. The results of the appraisal pointed that the experts agreed that the design process was very appropriate and accurate, with an overall score of 4.91 .

Table 4. Results of teaching and learning procedure assessment [48]

\begin{tabular}{|l|c|c|c|}
\hline \multicolumn{1}{|c|}{ Areas of assessment } & Mean & Mode & S.D \\
\hline Introduction & 4.78 & 5 & .384 \\
\hline Body & 4.71 & 5 & .317 \\
\hline Conclusion & 4.75 & 5 & .354 \\
\hline Assessment & 4.67 & 5 & .674 \\
\hline Overall & 4.73 & 5 & .041 \\
\hline
\end{tabular}

The evaluation of the teaching and learning procedure [48] included four processes: introduction, body, conclusion, and assessment. The results revealed that the experts 
Paper-A Design of Personal Learning Network on Social Networking Tools with Gamification for ...

agreed that the teaching and learning practice in this study was very appropriate with an overall score of 4.73 .

Table 5. Results of assessment of teaching and learning activities using PLNs on social networking tools with gamification in teaching and learning process

\begin{tabular}{|l|c|c|c|}
\hline \multicolumn{1}{|c|}{ Areas of assessment } & Mean & Mode & S.D \\
\hline Creation & 4.76 & 5 & .368 \\
\hline Connection & 4.76 & 5 & .368 \\
\hline Cognition & 4.75 & 5 & .387 \\
\hline Contribution & 4.88 & 5 & .299 \\
\hline Overall & 4.79 & 5 & .062 \\
\hline
\end{tabular}

The process of the personal learning network consists of Creation, Connection, Cognition, and Contribution. The evaluation of teaching and learning activities using PLNs on social networking tools with gamification in the context of the professional experience demonstrated the experts agreed that the teaching and learning activities were very appropriate, with an overall score of 4.79. Each area of assessment had a high mean score, as shown above.

\subsection{Discussion}

The SAM instructional design process was implemented in this study in order to design a teaching and learning process for professional experience program. According to the components of PLN in figure 1, the 4Cs process of PLN was implemented as learning activities within the learning context of professional experience procedure from figure 3 . These learning activities were performed on the social networking with gamification which operated as the learning tools. The $\mathrm{CN}$ was one of the learning tools that allowed learners to connect their learning resources including information, people, and networks. The designed framework of teaching and learning process for professional experience program is presented in figure 4.

In addition, the addable badges feature in the $\mathrm{CN}$ allowed the possibility for designing gamified-learning content. Therefore, the process of PLN was designed as learning activities parallel with the professional experience learning procedure utilizing the newly created addable badges, which was one of the gamification features on the $\mathrm{CN}$ platform. In order to receive all the badges, students have to enroll and join the $\mathrm{CN}$ by creating their new profile. The students are required to join the three seminars. While they go for their professional experience, the students participate by using PLN processes or activities on the $\mathrm{CN}$ to receive badges. The badges designed for the professional experience program are illustrated in Table 6. 


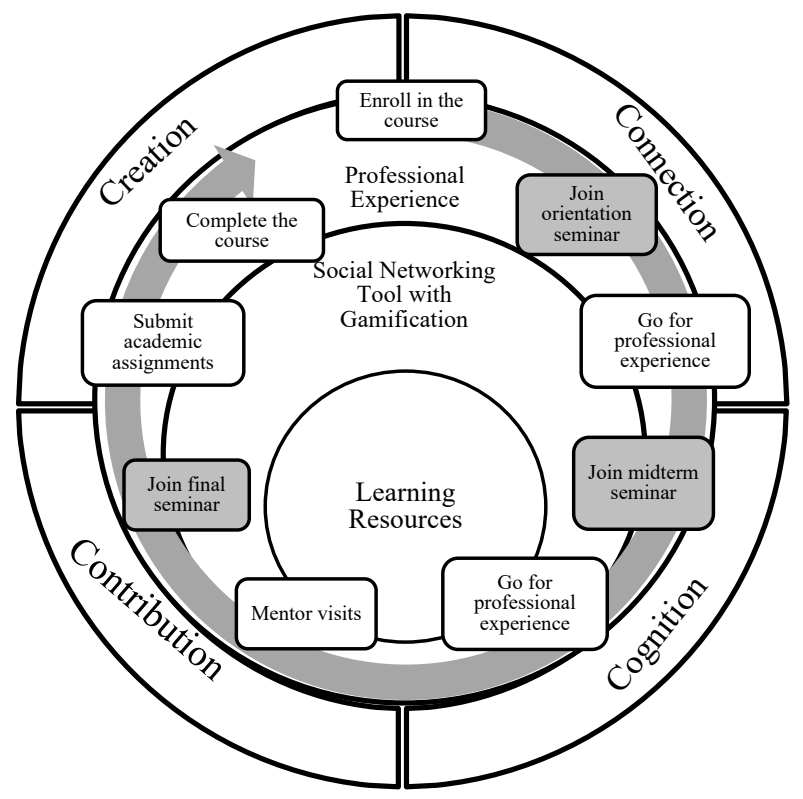

Fig. 4. Process of the professional experience program using PLN on social networking tools with gamification

Table 6. The badges designed for the professional experience

\begin{tabular}{|l|l|l|l|l|l|}
\hline & The Creator & & The Male Intern & \\
\hline & The Seminar & & The Female Intern \\
\hline
\end{tabular}

The results of the evaluation from the eleven experts could be discussed in five areas. First, the results of the standard of evaluation in Table 1 indicated a very good program standard. Second, the outcomes of the innovative attributes' assessment shown in Table 2 revealed a high level of observability and trialability, suggesting that the framework could be adapted to the similar context in other fields. Although the overall results were very high, it was suggested by some experts that the complexity regarding the use of new social networking tools could be a difficult issue in implementing this framework in other fields. In addition, software compatibility with the social networks familiar to most learners could be another obstacle. Third, the results of the design process appraisal indicated that the design steps were very appropriate and accurate. Fourth, the 
results of the teaching and learning procedure evaluation in Table 4 revealed that the teaching and learning practice using PLNs on social networking tools with gamification for the professional experience program was very appropriate. However, a few experts suggested that more details of the rubrics should be indicated, particularly for PLN learning activities marking. Finally, evaluation of the teaching and learning activities using personal learning network process revealed that the activities were very appropriate for the professional experience training program comprised of creation, connection, cognition, and contribution on social networking tools with gamification.

\section{Conclusion}

The purpose of this research aimed to create a new teaching and learning process using PLNs on social networking tools with gamification for the professional experience training program. The methodology of this research included three phases: preparation, iterative design, and iterative development, which were the stages of the SAM instructional design process. The implementation of PLN process was incorporated in learning activities parallel to the procedure of professional experience learning utilizing the present of addable badges as part of the gamification features on the social networking tool. Eleven experts were asked to evaluate the designed framework for teaching and learning procedure. The findings revealed that the experts agreed that the teaching and learning process using personal learning networks on social networking tools with gamification in the professional experience training program indicated high levels of standard evaluation, innovative attributes, design process, teaching and learning procedure, and teaching and learning activities. The experts' suggestions for improvement included adding more rubric details to the PLN learning activities assessment.

\section{References}

[1] Kemp, S. (2020). "More Then Half of The People On Earth Now Use Social Media," DataReportal: [Online]. Available: https://datareportal.com/reports/more-than-half-the-worldnow-uses-social-media/

[2] OECD (2020). Strengthening online learning when schools are closed: The role of families and teachers in supporting students during the COVID-19 crisis [Online]. https://doi.org /10.1787/c4ecba6c-en

[3] Li, C. \& Lalani, F. (2020). The COVID-19 pandemic has changed education forever. This is how, World Economic Forum [Online]. Available: https://www.weforum.org/agenda/ 2020/04/coronavirus-education-global-covid19-online-digital-learning/

[4] UNESCO (2020). Education in a post-COVID world: Nine ideas for bublic action International Comission on the Futures of Education. [Online]. Available: https://en. unesco.org/sites/default/files/education_in_a_post-covid_world-nine_ideas_for_public action.pdf

[5] Cha, H., Park, T. and Seo, J. (2020). What Should Be Considered when Developing ICTIntegrated Classroom Models for a Developing Country?, Sustainability, pp. 1-19. https://doi.org/10.3390/su12072967 
[6] Rapanta, C., Botturi, L., Goodyear, P., Guàrdia, L. and M. Koole (2020). Online University Teaching During and After the Covid-19 Crisis: Refocusing Teacher Presence and Learning Activity, Postdigital Science and Education, pp. 923-945. https://doi.org/10.1007/s42438020-00155-y

[7] Muhammad N. and Srinivasan, S. (2021). Online Education During a Pandemic Adaptation and Impact on Student Learning, International Journal of Engineering Pedagogy, vol .11, no .3, pp .71-83. [Online]. https://doi.org/10.3991/ijep.v11i3.20449

[8] Nguyen, H. (2021). Boosting Motivation to Help Students to Overcome Online Learning Barriers in Covid-19 Pandemic: A Case study. International Journal Of Interactive Mobile Technologies (IJIM), 15(10), pp. 4-20. doi:http://dx.doi.org/10.3991/ijim.v15i10.20319, https://doi.org/10.3991/ijim.v15i10.20319

[9] LaDue, D. S. and Cohen, A. E. (2018). Facilitating the Self-Directed Learning Efforts of Professional Meteorologists, American Meteorological Society, vol. 99, no. 12, pp. 25192527. https://doi.org/10.1175/bams-d-17-0324.1

[10] W. I. (2013). Deyamport, An Implementation of a Twitter-supported Personal Learning Network to Individualize Teacher Professional Development, (Doctoral dissertation).

[11] Grant, M. M. and Hsu, Y.C. (2014). Making personal and professional learning mobile: Blending mobile devices, social media, social networks, and mobile apps to support PLEs, PLNs, \& ProLNs., Advances in Communications and Media Research, vol. 10, pp. 27-46.

[12] Carter, T. J. and Nugent, J. S. (2011). Personal Learning Networks: Implications for SelfDirected Learning in the Digital Age, in Encyclopedia of Information Communication Technologies and Adult Education Integration, Long Beach, USA, IGI Global, p. 15, https://doi.org/10.4018/978-1-61692-906-0.ch014

[13] Al-dheleai, Y., Tasir, Z., Al-Rahmi, W., Al-Sharafi, M., \& Mydin, A. (2020). Modeling of Students Online Social Presence on Social Networking Sites with Academic Performance, International Journal of Emerging Technologies in Learning, vol. 15, no. 12, pp. 56-71. [Online]. https://doi.org/10.3991/ijet.v15i12.12599

[14] Hashimi, S. A., Muwali, A. A., Zaki, Y. E. and Mahdi, N. A. (2019). The Effectiveness of Social Media and Multimedia-Based Pedagogy in Enhancing Creativity among Art, Design, and Digital Media Students, International Journal of Emerging Technologies in Learning, vol. 14, no. 21, pp. 176-190. [Online]. https://doi.org/10.3991/ijet.v14i21.10596

[15] Kim, K. and Shin, S. C. J. (2015). Use of social media in different contexts of information seeking: effects of sex and problemsolving style, ERIC Institute of Education Sciences, pp. $1-10$.

[16] Aillerie, K. and Mcnicol, S. (2016). Are Social Networking Sites information sources?: Informational purposes of high-school students in using SNS, Journal of Librarianship and Information Science, vol. 1, no. 12, pp. 2-12. https://doi.org/10.1177/0961000616631612

[17] Kapoor, K. K., Tamilmani, K., Rana, N. P., Patil, P., Dwivedi, Y. K., and Nerur, S. (2018). Advances in Social Media Research: Past, Present and Future, Inf Syst Front, pp. 531-558. https://doi.org/10.1007/s10796-017-9810-y

[18] Raut, V. and Patil, P. (2016). Use of Social Media in Education: Positive and Negative impact on the students, International Journal on Recent and Innovation Trends in Computing and Communication, vol. 4, no. 1, pp. 281-285.

[19] Azizi, S. M., Soroush, A. and Khatony, A. (2019). The relationship between social networking addiction and academic performance in Iranian students of medical sciences: a crosssectional study, BMC Psychology, vol. 7, no. 28. https://doi.org/10.1186/s40359-019-0305$\underline{0}$ 
Paper-A Design of Personal Learning Network on Social Networking Tools with Gamification for ...

[20] Beemt, A. V., Thurlings, M. and Willems, M. (2020). Towards an understanding of social media use in the classroom: a literature review, Technology, Pedagogy and Education, vol. 29, no. 1, pp. 35-55. https://doi.org/10.1080/1475939x.2019.1695657

[21] Arnold, R., Santos, P. R. and Barbosa, D. N. (2020). A Gamification Model Applied to Social Network Education, EaD em Foco, vol. 10, no. 1, pp. 1-10.

[22] Deterding, S., Dixon, D., Khaled, R. and Nacke, L. (2011). From Game Design Elements to Gamefulness: Defining "Gamification", in MindTrek '11 Proceedings of the 15th International Academic MindTrek Conference: Envisioning Future Media Environments. https://doi.org/10.1145/2181037.2181040

[23] Laohajaratsang, T. (2017). Designing Effective Pedagogical Approaches with Next-Generation Learning Management System, Thaitesol Journal, vol. 31, no. 1, pp. 1-20.

[24] Flores, J. F. F. (2015). Using Gamification to Enhance Second Language Learning, Digital Education, pp. 32-54.

[25] Tobin, D. R. (1998). Building Your Personal Learning Network, Corporate Learning. [Online]. Available: http://www.tobincls.com/learningnetwork.htm/

[26] Trust, T. (2012). Professional Learning Networks Designed for Teacher Learning, Journal of Digital Learning in Teacher Education, vol. 28, no. 4, pp. 133-138. https://doi.org/10. 1080/21532974.2012.10784693

[27] Warlick, D. (2009). Grow Your Personal Learning Network: New Technologies Can Keep You Connected and Help You Manage Information Overload, Learning \& Leading with Technology, vol. 36, no. 6, pp. 12-16.

[28] American English (2015). Teacher's Corner: Personal Learning Networks (PLNs), July. [Online]. Available: https://americanenglish.state.gov/files/ae/resource files/background july final.pdf

Jarche, H. (2014). The Seek $>$ Sense $>$ Share Framework, Inside Learning Technologies\&Skills, vol. 47, pp. 13-14. [Online]. Available: http//:viewer.zmags.com /publication/38b45363\#

[30] Bauer, W. I. (2010). Your Personal Learning Network: Professional Development on Demand, Music Educator Jounal, vol. 97, no. 2, pp. 37-42. https://doi.org/10.1177 $\underline{10027432110386383}$

[31] Rajagopal, K., Brinke, D. J., Bruggen, J. V. and Sloep, P. B. (2012). Understanding personal learning networks: Their structure, content and the networking skills needed to optimally use them, First Monday, vol. 17. [Online]. https://doi.org/10.5210/fm.v17i1.3559.

[32] Nikolaou A. and Tsolakidis, C. (2013). Three Dimensional Virtual Environments a Tool for Development of Personal Learning Networks, International Journal of Emerging Technologies in Learning, vol. 8, no. 1, pp. 79-88. [Online]. https://doi.org/10.3991/ ijet.v8is1.2365

[33] Wheeler, S. (2010). Anatomy of a PLE. [Online]. Available: http://www.steve-wheeler.co. uk/2010/07/anatomy-of-ple.html

[34] Couros, A. (2010). Developing Personal Learning Networks for Open and Social Learning, Emerging Technologies in Distance Education, pp. 109-127.

[35] Swanson, K. (2012). Professional Learning in the Digital Age: The Educator's Guide to User-Generated Learning, 1st ed., New York: Routledge.

[36] Icha, O. and Edwin, A. (2015). Effectiveness of Social Media Networks as a Strategic Tool for Organizational Marketing Management, Journal of Internet Banking and Commerce, pp. 1-9. https://doi.org/10.4172/1204-5357.s2-006

[37] DeLaat, M. (2012). Enabling professional development networks: How connected are you?, Netherlands: Open Univerrsiteit, 2012. 
Paper-A Design of Personal Learning Network on Social Networking Tools with Gamification for ...

[38] Kiryakova, G., Angelova, N. and Yordanova, L. (2014). Gamification In Education, in 9th International Balkan Education and Science Conference.

[39] Panis, I. C., Setyosari, P., Kuswandi D. and Yuliati, L. (2020). Design Gamification Models in Higher Education: A Study in Indonesia, International Journal of Emerging Technologies in Learning, vol. 15, no. 12, pp. 244-255. [Online]. https://doi.org/10.3991/ijet.v15i12 $\underline{.13965 .}$.

[40] Kapp, K. (2014). Gamification: Separating fact from fiction, Chief Learning Officer, vol. 13 , no. 3, pp. $45-52$.

[41] Yamani, H. A. (2021). A Conceptual Framework for Integrating Gamification in eLearning Systems Based on Instructional Design Model, International Journal of Emerging Technologies in Learning, vol. 16, no. 4, pp. 14 - 33. [Online]. https://doi.org/10.3991 /ijet.v16i04.15693.

[42] Goshevski, D., Veljanoska, J. and Hatziapostolou, T. (2017). A Review of Gamification Platforms for Higher Education, in 8th Balkan Conference in Informatics, Skopje. https://doi.org/10.1145/3136273.3136299.

[43] Prathyusha, N. (2020). Role of Gamification in Language Learning, International Journal of Research and Analytical Reviews (IJRAR), vol. 7, no. 2, pp. 577-583.

[44] Chuenpraphanusorn, T., Snguanyat, O., Boonchart, J., Chombuathong, S. and Moonlapat, K. (2017). The Development of Work -Integrated Learning Model in Business Service Field for Rajabhat University, Thailand, Mediterranean Journal of Social Sciences, vol. 8, no. 1, p. 216. https://doi.org/10.5901/mjss.2017.v8n1p216.

[45] Allen, M. W. (2012). Leaving Addie for SAM: An Agile Model for Developing the Best Learning Experiences, ATD Press.

[46] Joint Committee on Standards for Educational Evaluation, Program Evaluation Standards, 2020. [Online]. Available: https://evaluationstandards.org/program/.

[47] Rogers, E. (2003). Diffusion of innovations, New York: Free Press, 2003.

[48] Smith, P. L. and Ragan, T. J. (1999). Instructional Design, John Wiley \& Sons, Incorporated.

\section{$7 \quad$ Authors}

Janejira Arsarkij is a candidate of Doctoral Degree Program in Faculty of Education, Chiang Mai University, Chiang Mai, Thailand. She currently works as the Head of Innovative Business Management Department, and the Head of International Business Management Program at the International College, Chiang Mai Rajabhat University, Chiang Mai, Thailand. Her research interest includes the integration of technology in learning, and the use of technology in business learning content.

Thanomporn Laohajaratsang is a learning technologist, an Associate Professor and Head of the Educational Technology Program at the Faculty of Education in Chiang Mai, Thailand. She currently serves as an Assistant to the President for Digital Technology and Corporate Communication affairs at Chiang Mai University. She also conducts projects and research activities related to the development of new media to support innovative pedagogies, the integration of ICT in educational system, and the design of future learning environments in both higher educational institutes and schools.

Article submitted 2021-06-23. Resubmitted 2021-07-28. Final acceptance 2021-07-29. Final version published as submitted by the authors. 